\title{
Síndrome das Pernas Inquietas e a estética barroca*
}

\author{
Restless Legs Syndrome and the Baroque esthetic* \\ Gilmar Fernandes do Prado', Luciane Bizari Coin de Carvalho², Karla \\ Carlos', Lucila Bizari Fernandes do Prado ${ }^{4}$
}

\section{RESUMO}

A síndrome das pernas inquietas (SPI) foi descrita pela primeira vez em 1672 por Thomas Willis (1621-1675), um brilhante médico Inglês que viveu durante o período Barroco. O Barroco é muitas vezes definido como a arte ou a cultura da Contra-Reforma, uma expressão de valores específicos que eram inerentes ao estado de conflito da alma humana durante esse tempo. O sintoma cardinal da SPI é um compulsivo e irresistível desejo de mover as pernas. É uma disposição interior para a inquietaçâo, que também está presente em todas as manifestaçóes artísticas do Barroco. Os sintomas da SPI expressam as antíteses de repouso e movimento, calma e tempestade, estabilidade e desequilíbrio, de superfície e de profundidade. Acreditamos que o Barroco foi um importante contribuinte para a descrição da SPI e que a SPI é uma condição que se expressa de forma semelhante à de arte barroca (por exemplo, textos, pinturas, etc). Durante o tempo em que Willis viveu, todas as manifestaçôes culturais eram do Barroco. Estes incluíram movimento, assimetria, contraste, cor lúgubre e harmonia, deslocados pelo desequilíbrio. Além disso, o período do Barroco foi necessário para a SPI para vir a ser.

Unitermos. Síndrome das Pernas Inquietas, Sensação, Transtornos do Sono

Citaçáo. Prado GF, Carvalho LBC, Carlos K, Prado LBF. Síndrome das Pernas Inquietas e a estética barroca.

Trabalho realizado no Setor de Neuro-Sono, Escola Paulista de Medicina, UNIFESP, São Paulo-SP.

1.Neurologista, Livre-docente, Professor Adjunto, Setor Neuro-Sono, Escola Paulista de Medicina, Universidade Federal de São Paulo, São Paulo-SP, Brasil. 2.Psicóloga, Doutora, Professora Afiliada da Disciplina de Neurologia, Setor Neuro-Sono, Escola Paulista de Medicina, Universidade Federal de São Paulo, São Paulo-SP, Brasil.

3.Fisioterapeuta, Mestranda, Setor Neuro-Sono, Escola Paulista de Medicina, Universidade Federal de São Paulo, São Paulo-SP, Brasil.

4.Médica, Doutora, Coordenadora do Laboratório de Sono Hospital São Paulo e do Laboratório de Pesquisa Neuro-Sono, Escola Paulista de Medicina, Universidade Federal de São Paulo, São Paulo-SP, Brasil.

\section{ABSTRACT}

Restless legs syndrome (RLS) was first described in 1672 by Thomas Willis (1621-1675), a brilliant English physician who lived during the Baroque. The Baroque is often defined as the art or culture of the Counter-Reformation, an expression of specific values that were inherent to the conflicted state of the human soul during that time. The cardinal symptom of RLS is an imperious, compulsive, irresistible urge to move one's legs. It is an inner disposition towards disquiet, which is also present in all artistic manifestations of the Baroque. The symptoms of RLS express the antitheses of rest and motion, calm and storm, stability and imbalance, surface and depths. We believe that the Baroque was an important contributor to the description of RLS and that RLS is a condition expressed similarly to that of Baroque art (e.g., writings, paintings, etc). During the time when Willis lived, all cultural manifestations were of the Baroque. These included movement, asymmetry, contrast, lurid color, and harmony displaced by imbalance. Furthermore, the period of Baroque was necessary for RLS to come to be.

Keywords. Restless Legs Syndrome, Sensations, Sleep Disorders

Citation. Prado GF, Carvalho LBC, Carlos K, Prado LBF. Restless Legs Syndrome and the Baroque esthetic.

*Parte deste artigo foi publicado como Carta ao Editor na revista Sleep Medicine 2013;14:470-11, doi: 10.1016/j.sleep.2013.01.004. A reprodução da publicação em língua portuguesa foi autorizada pelos autores e pela Elsevier.

Endereço para correspondência: Lucila F Prado Rua Cláudio Rossi, 394 Vila Mariana Cep: 01547-040, São Paulo-SP, Brasil. Tel/fax: (11) 50816629 Email: neuro.sono.unifesp@gmail.com 
Dados Históricos. A Síndrome das Pernas Inquietas (SPI) foi descrita em 1672 por Thomas Willis, um brilhante médico que viveu na Inglaterra entre 1621 e 1675, durante o período barroco (Figura 1$)^{1}$. Alguns autores argumentam que o barroco não foi tão intenso naquele país relativamente à Espanha, Portugal, Itália, Brasil (ainda parte da corte portuguesa) e Alemanha ${ }^{2-4}$, no entanto é plenamente reconhecível na produção artística e cultural Inglesa expressóes de angústia típicas do barroco como a que consome Hamlet em William Sheakespeare ${ }^{5,6}$.

O momento em que se inicia esta peculiar forma de expressão artística humana varia conforme se considere o tipo de arte produzida, havendo ainda imbricamentos de estilos caracterizados por obras de transição tanto no extremo inferior quanto superior daquele período ${ }^{7}$. Apenas como marcos referenciais, e cada país admitirá um período específico, podemos dizer que o período barroco iniciou-se após a segunda metade do século XVI, chegando também à segunda metade do século XVIII, sendo seu período mais expressivo aquele dos anos seiscentos ${ }^{2}$. Alguns críticos consideram que mesmo no século XX podem ser reconhecidas manifestaçóes artísticas de caráter barroco, não sendo então um movimento com definição temporal estanque ${ }^{8}$.

O homem ocidental ao longo de mais de 100 anos, entre o Humanismo e o Iluminismo, esteve imerso nesta atmosfera cultural, e várias geraçôes de seus descendentes receberam sua influência ${ }^{9}$. A este robusto aspecto da cultura ocidental seguiu-se o Neoclassissismo e logo a seguir o Romantismo por volta de 1760, quando na Europa começam a surgir manifestaçóes destinadas a combater a estética barroca, propondo-se o retorno à simplicidade clássica ${ }^{10}$.

O Barroco. A palavra pode ter se originado do Português "barroco" ou do Espanhol "barrueco", ambas significando pérola imperfeita (irregular), um significado que foi mais valorizado por críticos que não reconheciam o barroco como arte $\mathrm{e}^{7,9,11}$. Embora, na opinião de René Wellek, o real sentido de uma palavra não possa ser evocado com precisão fora do momento histórico em que foi usada, o próprio autor entende que tal termo teve origem na nomenclatura escolástica do silogismo, onde tal palavra referia-se ao segundo termo. É bastante representativo o exemplo de Benedetto Croce: "Todo tolo é teimoso; algumas pessoas não são teimosas; logo algumas pessoas não são tolas" ("Every fool is stubborn; some people are not stubborn; hence some people are not fools"), onde podemos perceber certo desconforto diante das assertivas, mesmo antes de entender a armadilha lógica.

Estas visôes divergentes parecem integrar a concepção mesma do barroco, refletindo um espectro intrincado e complexo. E por essa razão que dentro do campo biológico a palavra barroco tem sido empregada com o

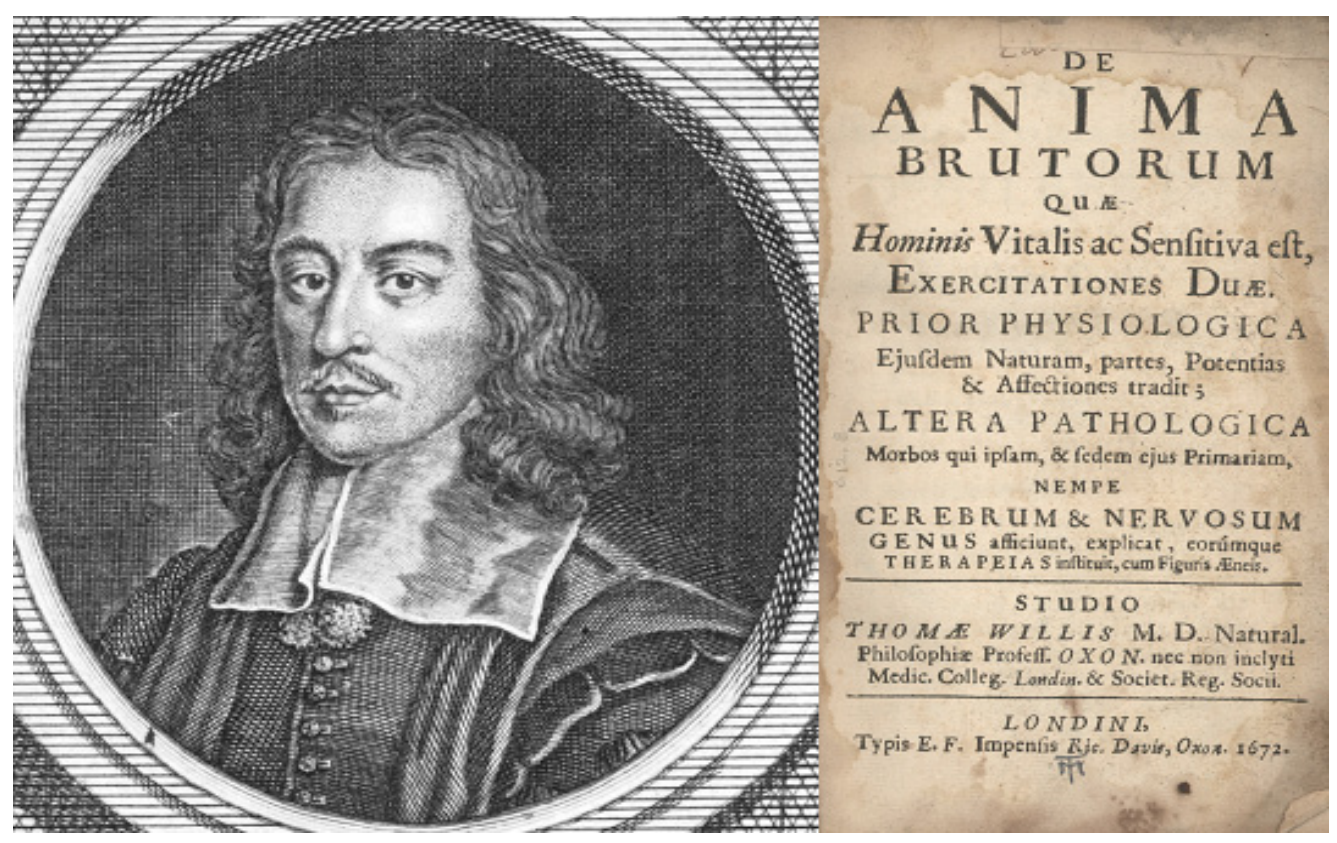

Figura 1. Thomas Willis (1621 - 1675) e a capa do livro Anima Brutorum, no qual se encontra a descrição da SPI. 
significado de complexidade, um aspecto praticamente indiscutível, independentemente do conceito subjacen$\mathrm{te}^{12-14}$.

Até praticamene a década de 30 no século XX, o Barroco era entendido como manifestação cultural de mau gosto, bastando para compreender tal julgamento a expressão de Croce: "Art is never baroque, and the Baroque is never art". Já por volta de 1945 o barroco ficou largamente estabelecido tanto como um período histórico relacionado a uma fase da cultura ocidental que se seguiu ao renascimento, quanto um conceito psicológico abstrato para designar o tipo de expressão que pode ocorrer em qualquer cultura histórica e eventualmente reaparecer em seus vários estágios de desenvolvimento ${ }^{15}$. O barroco foi então redescoberto e resignificado no século $\mathrm{XX}$, um processo que envolveu a pesquisa especializada, a interpretação e a disseminação da nova concepção. Uma estética que repousa na exaltação das formas clássicas e suas expressóes, e que ensejou a idéia de decadência e mau gosto durante muitos anos, é ressucitada pelos estudos de história da arte de Heinrich Wölfflin ${ }^{8,16}$.

Características do Barroco. O barroco é muitas vezes referido como a arte, a estética ou a cultura da Contra-Reforma ${ }^{16}$, exprimindo valores específicos e inerentes ao estado conflitivo da alma humana naquele período da história; mas a Contra-Reforma em si também é vista como um sintoma de uma profunda crise intelectual da época, que se instalou em bases políticas e teve no barroco uma oportunidade de expressão, e não a influência determinante ${ }^{17}$. A arte barroca comporta valores contraditórios, mas em todos os estilos pode-se reconhecer uma exuberância e veemência geral. As expressóes mais visíveis do barroco podem ser observadas nas igrejas, onde abundam as nuvens, detalhes, anjos gesticulando, e tudo parece mover-se e dançar ${ }^{18}$.

$\mathrm{Na}$ literatura o estilo barroco compóe-se de formas típicas como os epítetos magnificantes, palavras ressonantes, repetiçôes silábicas e de palavras, complicada estrutura das sentenças, ritmo lento, imagens impressionantes e unificadas ${ }^{16}$, que na concepção de Eugenio D'Ors, reflete a emancipação humana da terra ${ }^{13}$. Desde Wolfflin se admite que o nível de percepção artística esteja sujeito a causas sociológicas externas, as quais determinam as mudanças de um estilo para outro ao longo da história, sendo estas sujeitas a leis internas ${ }^{15}$.

Ao olharmos para Santa Catarina de Alexandria (Rafael, 1483-1520, Figura 2) percebemos harmonia e simetria tal que nâo sentimos necessidade de vermos o lado direiro de sua face. Os olhos da santa não estão no plano terrestre, mas o além a que se dirigem está bem próximo a ela, e seu rosto ilumina-se com ele: é a finitude clássica, o mundo ordenado em esferas concêntricas, ordenado e regido pelas leis da perfeição. Apesar de ocupar o primeiro plano da tela, como ocorre no barroco, encontra-se integrada ao cenário, sendo coerente com o todo, transmitindo-nos a paz ensejada em tal harmonia, tipicamente expressa na pintura renascentista. A obra reflete a racionalidade típica da estética, onde a simetria ( $\sigma \nu \mu \mu \varepsilon \tau \rho 1 \alpha$ - with measure) enseja a harmoniosidade, traduzindo a primitiva e equivalente acepção grega das palavras simetria-harmonia, que também se relaciona às concepçôes Euclidianas de proporções e racionalidade ${ }^{19}$. Dagoberto Frey resume de forma elegante os significados aludidos "Symmetry signifies rest and binding, asymmetry motion and loosening, the one order and law, the other arbitrariness and accident, the one formal rigidity and constraint, the other life, play, and freedom" 17 .

Bem diferente é "The girl with the pearl earing" (Vermeer, 1632-1675, Figura 3), onde a imagem ocupa o primeiro plano emergida de um fundo escuro, desvinculando-a do previsível, das normas, leis; ao contrário, conferindo-lhe o mistério da face humana, sugerindo-lhe expressóes de indivisada origem, algo bem distante das leis gerais do mundo finito, mas próprios e bem particulares de uma e única pessoa. Jorram diferenças entre as obras de reconhecida beleza femininas: uma santa, uma desconhecida; paz e tensão; repouso e movimento; no mundo, sozinha; monótona, surpreendente; simples, complexa; relação com o quadro, relação com o observador. A garota parece fitar o observador não importa de onde ele a olhe, parecendo ter acabado de se virar ao seu encontro. Ela carrega uma preocupação, mas se encontra resignada. Sua condição e estado psíquico é mais facilmente percebido quando a comparamos com a personagem de Scarlett Johansson (Peter Webber, 2003, Figura 4). "The girl with the pearl earing by Scarlett Johansson" não parece verter aquela leve ansiedade e preocupação já aludidas, mas al- 


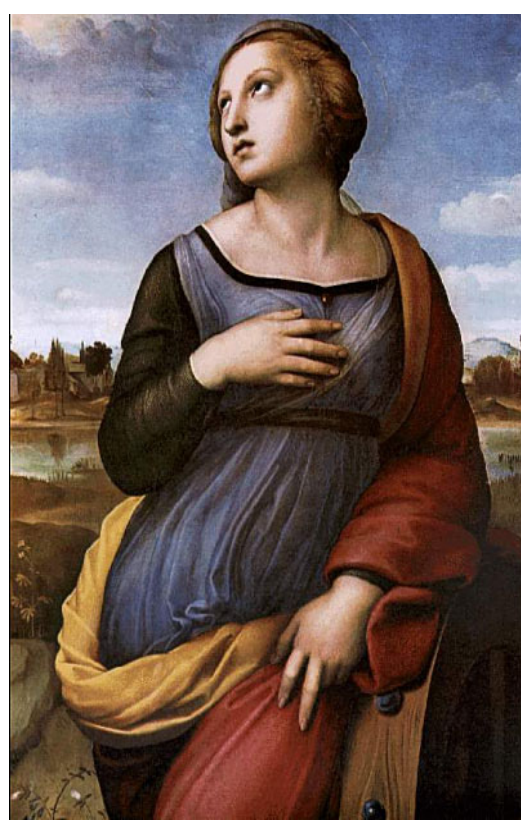

Figura 2. Santa Catarina de Alexandria (Rafael, 1483-1520)

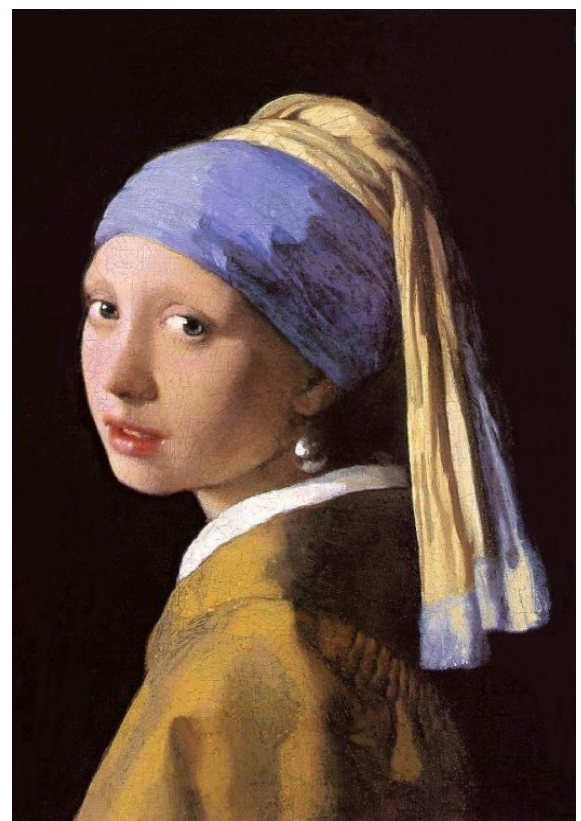

Figura 3. The girl with the pearl earing (Vermeer, 1632-1675)

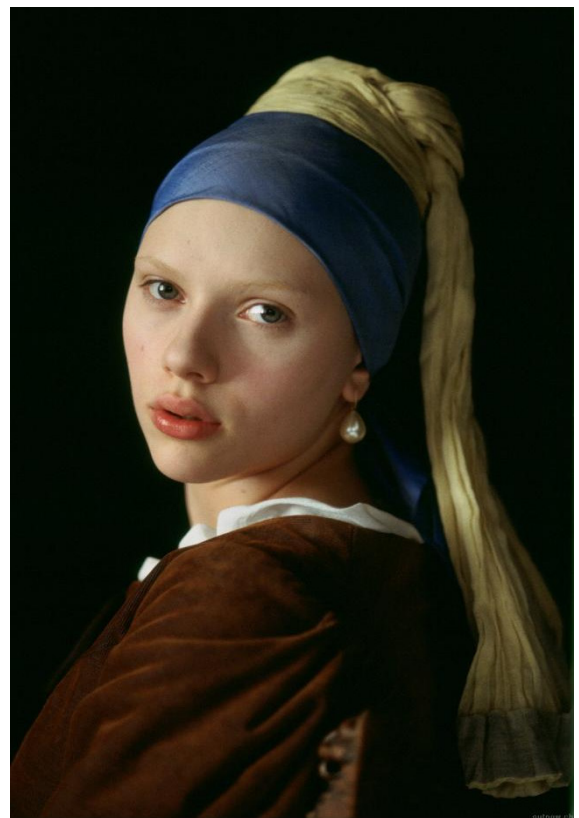

Figura 4. The girl with the pearl earing by Scarlett Johansson (Peter Webber, 2003) guma tristeza. "The Girl-Scarllet" se mostra mais segura e algo cansada, deixando entrever um abandono que não se pode supor se de si ou do mundo, mas no tempo, na história, tipificada em suas vestes que lhe conferem seu estado de deslocamento do real. Seu olho direito é triste, crítico e julgador; seu olho esquerdo é curioso (em relação a quem lhe observa), parece deslocado para cima e distante do observador; faz par com seus lábios, conferindo ao conjunto um tom mais sensual que o "The Girl-Vermeer". Parece que "The Girl-Vermeer" está mais afastada e também conformada com a distância que a separa de seu observador, esboçando em seu lábio superior tênue sorriso de reconhecimento pela sintonia ensejada, como quem, em sua abdicação, apaziguou a consciência ante o real.

Síndrome das Pernas Inquietas. É uma doença que se configura quase que exclusivamente no âmbito do subjetivo, havendo poucas manifestações reconhecíveis externamente ao próprio indivíduo afetado, como é o caso dos movimentos periódicos dos membros de alta amplitude ${ }^{20}$. Afora esse aspecto motor, o real sofrimento imposto ao paciente por essa doença advém de sintomas íntimos e pouco exprimíveis vernacularmente. São sintomas quase que indescritíveis, contribuindo para o estado penoso do afetado, ampliando a angústia ante uma condição intrinsecamente contraditória: sofrimento em face do repouso. Aqui o artista deitou seu pincel para construir um fundo clássico, harmônico e fez emergir em primeiro plano uma figura humana em indefinida dor. Ali o artista tomou a história de sofrimento e elaborou um fundo sombrio, indefinido, matizado, pictórico ou negro; deixou entrever o sofrimento, a resignação, o desamparo, o mistério e lacônicas palavras, buscando tocar o indizível.

O paciente afetado pela SPI pode ser reconhecido por quatro características dessa doença: 1) O paciente apresenta uma necessidade incontrolada, imperiosa de mover as pernas, na grande maioria das vezes motivada por sensaçóes desagradáveis nas pernas, quase sempre indescritíveis ou estranhas; 2) A sensação desagradável nas pernas ou a necessidade íntima de movê-las surge durante o repouso, como sentar-se para descansar, relaxar ou deitar-se para dormir; 3) Os sintomas pioram ou surgem à noite, principalmente no horário de dormir; 4) Os sintomas melhoram com a movimentação das pernas, principalmente quando o paciente anda, e na maioria das vezes volta pouco tempo após ter parado de movê-las ${ }^{21,22}$.

Esta sintomatologia impede que o paciente inicie ou mantenha o sono, podendo ser táo grave que o paciente só consiga dormir algumas horas no final da madrugada, sendo, portanto, a insônia uma das principais consequências desta doença ${ }^{22}$. $\mathrm{O}$ movimento de pernas 
é compulsório, ocorrendo involuntariamente quando o paciente retém o ímpeto interior em movê-las ${ }^{20}$. À noite é possível se observar os abalos nos membros, os quais ocorrem em quase $80 \%$ dos pacientes, sendo visíveis apenas os mais intensos ${ }^{23}$.

Willis descreveu a SPI em uma senhora que apresentava grande inquietude quando se colocava em repouso ou quando se deitava para dormir ${ }^{2,3}$. Valeu-se para isso da Doutrina dos Nervos ${ }^{3}$, a qual presumia movimento dos espíritos animais através destas estruturas à semelhança do que demonstrou Harvey em relação ao movimento do sangue nos vasos. Harvey e Willis foram vizinhos na Merton Street, Oxford ${ }^{24}$.

Sauvage em 1763, entấo no período barroco, fez nova referência à SPI, chamando de Anxietas tibiarum uma condição em que o paciente apresentava sintomas nas pernas, inquietude interior, melhora com o movimento, e (estranhamente) também com o repouso, algo não esperado, já que consideramos essencial ao diagnóstico o surgimento dos sintomas em associação com o repouso. Sauvages também não descreveu a piora noturna ${ }^{25}$.

SPI: um quadro barroco. O sintoma cardinal da SPI é a necessidade imperiosa, compulsiva, irresistível de mover as pernas. É uma disposição interior de inquietude, algo presente em todas as manifestações artísticas do período barroco. Esta sintomatologia exprime a antítese repouso-movimento, calma-tormenta, estabilidade-desequilíbrio, superfície-profundeza. "A Tempestade" de Giorgione (Giorgio Barbarelli da Castelfranco, 1477 a 1510, The Tempest, Figura 5), emblemática obra da Renascença, exprime o paradoxo da SPI: a tormenta ao fundo ameaçando o repouso e harmonia da paisagem e personagens. A ordem, calma, paz e repouso das personagens tem seu fim anunciado, pois uma tempestade se forma ao fundo. Eles serão obrigados a se mover.

O paciente acometido pela SPI não se encontra bem dentro do mundo ${ }^{26}$. Está angustiado e ansioso. Não pode contar com seus semelhantes para amenizar seu sofrimento, está só, e deve resignar-se ante sua condição, pois já não pode mais ser compreendido. Suas sensaçôes interiores parecem referir-se somente a si: o resto do mundo é puro cenário ao qual o paciente deve se adequar. $\mathrm{O}$ paciente se cala. Mas procura cumprir suas demandas sociais. Não conseguindo provar ao outro o que lhe aflige, parece estranho ao mundo. Não conseguindo se fazer ver na interioridade de sua dor, resigna-se na rotina constante: está sempre ativo, nunca para, não se cansa e pouco dorme. Não lhe foi permitido o repouso, relaxar e perceber seu corpo revigorar.

"The girl with the pearl earing" (Vermeer) sugere essa resignação. A garota parece não estar completamente

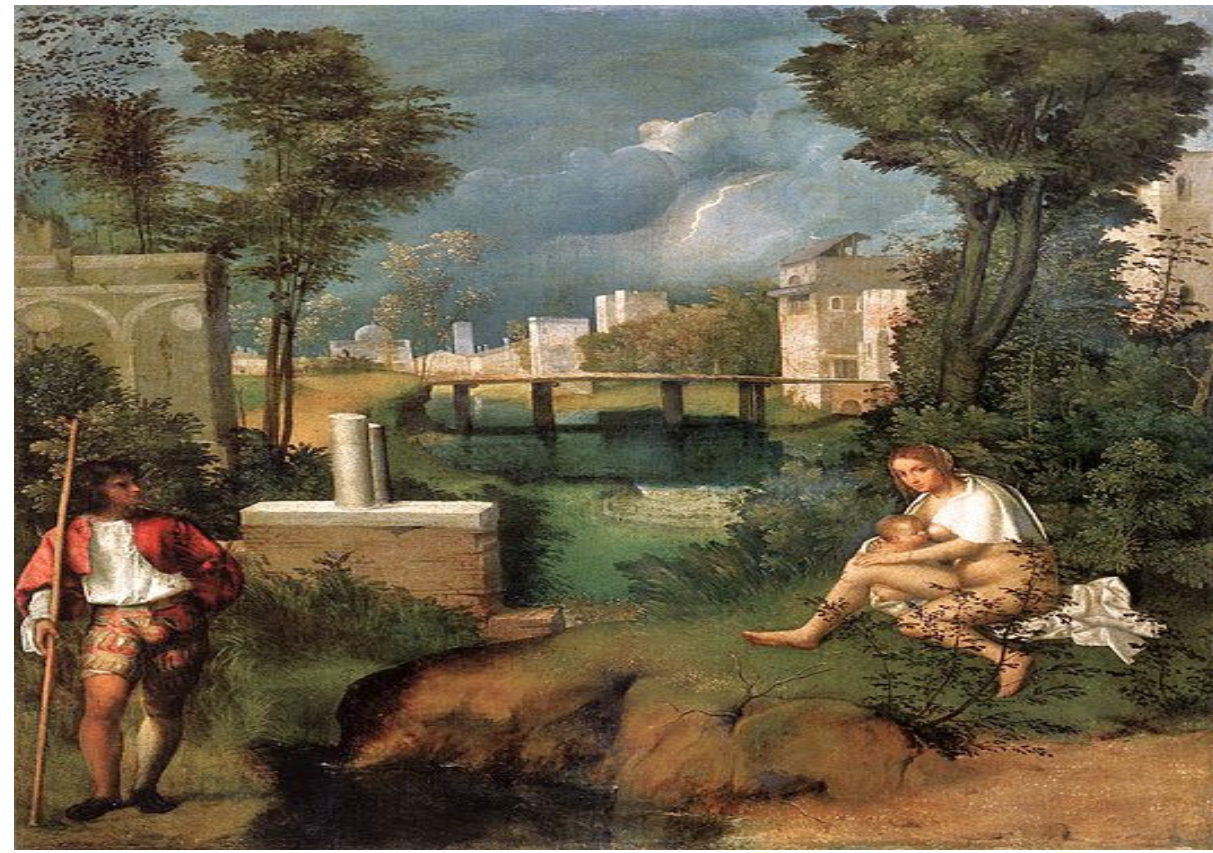

Figura 5. Giorgione (1477-1510). The Tempest. 
feliz, mas tolera sua condiçâa. A garota é desconhecida.

A SPI não é de conhecimento geral ainda hoje. Embora os médicos já tenham ouvido falar da doença, os pacientes ainda não ouviram. Embora os médicos possam diagnostica-la, poucos efetivamente conseguem trata-la apropriadamente. Os ollhos da garota, ao mesmo tempo, talvez pela sua idade, parecem pedir alguma ajuda. Pacientes que longamente sofrem da doença, parecem já desapegados, e conformados surpreendem-se com o nome e a descoberta de sua condição. Podem chorar aliviados como em um encontro entre distantes pessoas que se queriam; choram por se verem de volta a si mesmos, por terem reencontrado o que lhes apartava de sua própria psiquê, levados distantes pelas próprias pernas que os recolhem de volta na unidade. Verdadeiro conflito. Doença barroca.

Vivência barroca em Willis. No período em que Willis viveu as manifestações culturais eram de estética barroca. O movimento, assimetrias, contrastes, cores lúricas; o desequilíbrio toma o lugar da harmonia. A própria obra "De Anima Brutorum" em que Willis descreve a SPI, tem um nome tipicamente barroco: "De anima brutorum qua hominis vitalis ac sensitiva est, exercitationes dua" que em Português seria "Duas dissertaçóes acerca da alma animal que é a vital e a sensitiva do homem"2. O movimento estava presente na ciência de Harvey ou na pintura de Daniel Mytens (Figura 6) retratando o Rei Charles I e a Rai- nha Henrieta saindo para a caça. A fisiologia do sistema nervoso em Willis funda-se no movimento dos espíritos animais, que se infletem para as várias regióes do cérebro ou do corpo através dos nervos, promovendo o comportamento. Estes espíritos animais represados em dobras dos nervos provocavam as parestesias e dores. Durante a noite, caso não voltassem ao cérebro, onde repousariam, poderiam causar tormenta ao corpo ${ }^{3}$. Na estética barroca o linear (sentido pelas mãos) cede lugar ao pictórico (painterly; para ser seguido pelos olhos); disposição plana (para ser sentida) dá lugar à disposição em profundidade (para ser seguida); as partes subordinam-se ao todo; no lugar do estilo fechado que barra o observador surge o estilo aberto que inclui o observador, levando-o para o interior da cena (Heinrich Wolfflin). A própria descrição de Willis é carregada de emoçóes:

“os espíritos que foram chamados de seu estado de contínua vigília, e direcionados ao tronco cerebral, podem transferir seus tormentos à medula espinhal, e deste ponto aos nervos que passam por todos os membros, motivo pelo qual, quando no leito, pondo-se a si mesmos para dormir, logo provocam, nas pernas e nos braços, abalos e contraçóes dos tendóes, e tão grande a inquietude e o remeximento dos membros, que o paciente é incapaz de dormir, sendo mais penoso que estar numa prancha de tortura."

O homem barroco em seu conflito está mais aberto aos dramas da alma e pode interagir no espaço terreno, incluindo suas próprias vertentes, mesmo quando se reporta a Deus. O homem barroco ouve os ecos de suas

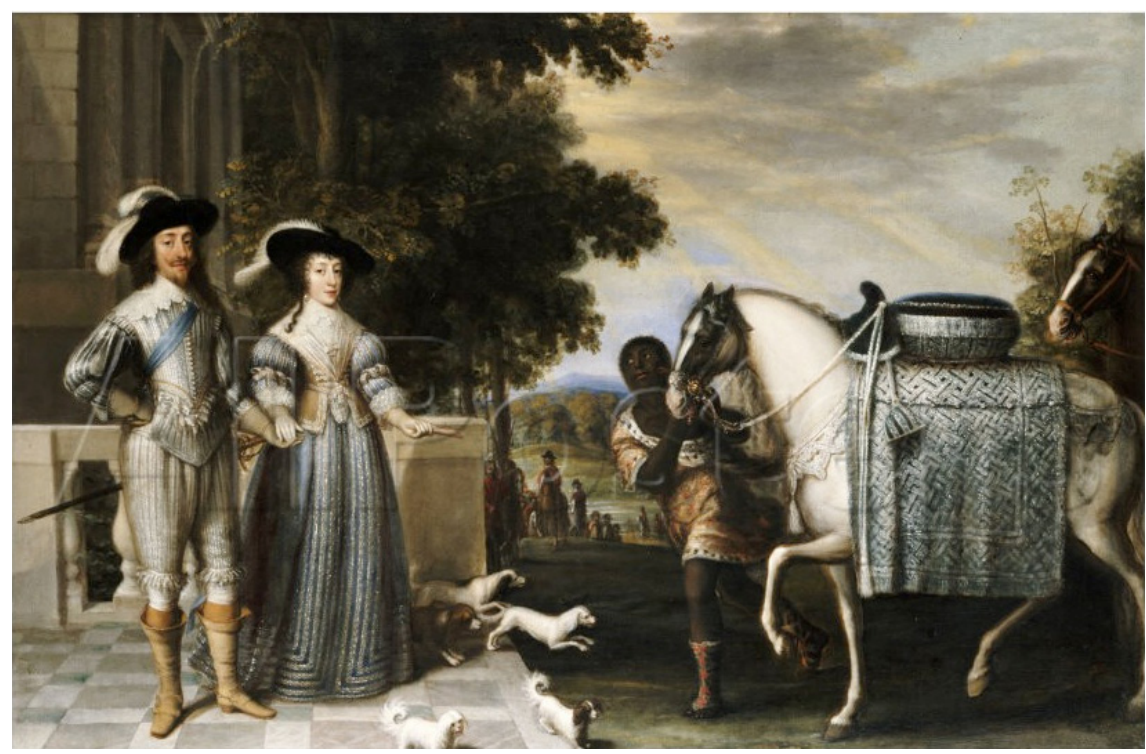

Figura 6. Rei Charles I e Rainha Henrieta. (Daniel Mytens). 
vivências na linguagem do outro, na pintura, na prosa, na poesia, na música. Não é possível desvincular completamente um homem de seu mundo cultural, assim os ecos barrocos chegaram à medicina de Willis, e ele pode ver bem além dos que o antecederam, descrevendo várias doenças, dentre elas a SPI, uma doença com manifestações subjetivas e que requer ao médico participar do quadro, adentrar ao mundo dos sintomas, para percebê-los e interpreta-los.

The girl with the pearl earing. A SPI não deixará de ser uma doença barroca, e continuará movendo o médico ao interior de cada quadro, quadro clínico. $\mathrm{O}$ paciente que porta a doença sabe de sua condição crônica, cuja mudança de estado é dependente de grande esforço de tratamento. O paciente sabe que os olhos que o veem não o enxergam na profundidade, e mesmo que conheçam sua dor, dela podem presumir apenas breves lampejos. Mas o paciente olha de volta ao observador, como na pintura de Vermeer, pedindo-lhe ajuda, mas sem se demover da resignação. Se "The girl-Vermeer" pode simbolizar a SPI, "Griet's Theme (reprise)", de Alexandre Desplat, pode simbolizar esse afeto autoapaziguador e cúmplice com o mundo que não pode ser completamente mudado, e no caso da SPI, apesar dos tratamentos disponíveis.

Neste cenário de complexidade de uma doença barroca, cabe ao médico reconhecer luzes, tons, afetos e ouvir o interior de cada paciente. Formar a figura sob o contraste que fortemente subjaz à SPI: a angústia, a inquietude, a premência, necessidade e imperiosidade de movimento suscitada por este não estar bem no mundo: o desconforto barroco. O médico que adentra ao que o quadro lhe convida, correrá menos chances de não perceber as várias nuances sintomáticas que parecem mimeti$\operatorname{zar}^{27}$ a SPI.

Em suma, o Barroco permitiu que a SPI pudesse tornar-se dizível, e pode ter sido essa mudança na cultura, essa atenção aos conflitos, paradoxos humanos, assimetrias e tensão terra-céu que deu chance ao seu reconhecimento no espaço da linguagem, como sugere Foucault ${ }^{28}$. Os estudos que vem mostrando a SPI associada ao metabolismo cerebral do ferro ${ }^{29}$ estão trazendo também a SPI ao espaço do visível, completando a concepção foucaultiana.
Não há como não se pensar que a SPI não tenha a idade do próprio homem, mas existia num mundo aparte, distante da linguagem, como os hiperbóreos de Nietzsche. Foi necessário o Barroco para lhe dar palavras com significado e ouvidos que a compreendessem. Foi preciso que toda humanidade ocidental sofresse o desconforto de estar no mundo, vivesse o paradoxo finito-infinito, homem-deus, terreno-divino e a solidão e frustração de não ser o centro do universo, para que pudesse ser ouvido em seu mais íntimo afeto. Se tomássemos de empréstimo o olhar de Merleau-Ponty ${ }^{30}$, a SPI foi uma criação do Barroco. Entre essa figura clínica aparentemente indiscutível do real, instituída em palavras e imagens costuradas de uma razão, própria do discurso, há o momento de instituição, proposição, onde a essência secreta do objeto passa à existência. A criação pode se dar pela mão do pintor, do escritor, do pensador. A essência secreta da SPI foi desvelada ao espaço do real pelo médico. E foi preciso um momento instituinte particular para que a SPI pudesse vir a ser: o Barroco.

Conclusão. Uma pintura barroca, a SPI, deixa cores fortes na tela. Ao fundo a paz do repouso, o descanso do corpo que labora, a integração harmônica dos sentidos. O deleite do sono. Mas, à frente, saltitam dissonâncias, assimetrias e angustioso castigo à acomodação do corpo no desejo de se encontrar, unir-se a si mesmo e saborear a calma e silêncio da tarde e da noite. Vê-se, nesse quadro, que o sol fez seu caminho ao ocidente e foi deixando o frescor e brisa aos seres que se guardam à noite. Quando então o fundo torna-se indiviso, a estampa se contorce em aflição. A mão do pintor moveu-se inquieta diante da tela, e neste leito deitou cores e sombras incontidas, barrocas: a SPI.

\section{REFERÊNCIAS}

1.Prado GF, Carvalho LBC, Carlos K, Prado LBF. The Baroque and its influence on Willis' description of restless legs syndrome. Sleep Med 2013;14:470-1. http://dx.doi.org/10.1016/j.sleep.2013.01.004

2.Prado GF. Síndrome das pernas inquietas: há quanto tempo será ignorada? Rev Neurocienc 2002;10:38-43. http://dx.doi.org/10.4181/RNC.2002.10.38 3.Willis T. Anima Brutorum. London: Wells and Scott, 1672, p 339-41.

4.Praz M. Baroque in England. Modern Philol 1964;61:169-79.

5.Arriola PM. Two Baroque Heroes: Segismundo and Hamlet. Hispania 1960; $43: 537-40$. 
6.Barasch FK. Definitions: Renaissance and Baroque, Grotesque Construction and Deconstruction. Modern Lang Stud 1983;13:60-7.

7.Hall Jr RA. Meditation on a Baroque Theme. Modern Lang J 1962;46:3-8. http://dx.doi.org/10.1111/j.1540-4781.1962.tb00788.x

8.Kaup M. Becoming-Baroque: Folding European Forms into the New World Baroque with Alejo Carpentier. New Centen Rev 2005;5:107-49. http:// dx.doi.org/10.1353/ncr.2005.0043

9.Hatzfeld H. A Clarification of the Baroque Problem in the Romance Literatures. Comp Literat 1949;1:113-9.

10.Passmore J. History of Art and History of Literature: A Commentary. New Literar Hist 1972; 3:575-87.

11. Wellek R. The concept of baroque in literary scholarship. J Aesthet Art Critic 1946;5:77-109.

12.Lewin R. A Baroque Turn for Intron Processing. Science 1982;218:1293-5. 13.Kuo S, Chang WJ, Landweber LF. Complex Germline Architecture: Two Genes Intertwined on Two Loci. Mol Biol Evol 2006;23:4-6. http://dx.doi. org $/ 10.1093 / \mathrm{molbev} / \mathrm{msj} 017$

14.King MR, Steenbergen SM, Vimr ER. Going for baroque at the Escherichia coli K1 cell surface. Trends Microbiol 2007;15:196-202. http://dx.doi. org/10.1016/j.tim.2007.03.006

15.Hassold EC. The Baroque as a Basic Concept of Art. College Art J 1946;6:3-28.

16.Hatzfeld H. Estudos sobre o barroco. São Paulo: Editora Perspectiva, 2002, 320 p.

17.Frey D. Translation of Letter from Dagobert Frey. College Art J 1947; 6:305-6.

18.Martins M. De corpo e alma. Psicanal Barroco Rev 2008;6:75-85.

19.Lorenz K. Reflections on the concept of symmetry. Eur Rev 2005;13:3-11. http://dx.doi.org/10.1017/S1062798705000621

20 Hening WA, Allen RP, Washburn M, Lesage S, Earley CJ. Validation of the Hopkins telephone diagnostic interview for restless legs syndrome. Sleep Med 2008;9:283-9. http://dx.doi.org/10.1016/j.sleep.2007.04.021
21.Allen RP, Picchietti D, Hening WA, Trenkwalder C, Walters AS, Montplaisi J. RLS: diagnostic criteria, special considerations, and epidemiology. A report from the restless legs syndrome diagnosis and epidemiology workshop at the National Institutes of Health. Sleep Med 2003;4:101-9. http://dx.doi. org/10.1016/S1389-9457(03)00010-8

22.Earley CJ. Restless Legs Syndrome. N Engl Med 2003;348:2103-9. http:// dx.doi.org/10.1056/NEJMcp021288

23.Lugaresi E, Tassinari CA, Coccagna G, Ambrosetto C. Particularités cliniques et polygraphiques du syndrome d'impatiences des membres inférieurs. Rev Neurol 1965;113:545-55.

24.Molnár Z. Thomas Willis (1621-1675), the founder of clinical neuroscience. Nat Rev Neurosci 2004;5:329-35. http://dx.doi.org/10.1038/nrn1369

25.Sauvages FB. Dolores et Vesanias. In: Nosologia Methodica: sistens morborum classe, genera et species. Tome tertii pars prima. Veneza: Typis \& Impensis Nicolai Pezzanae, 1763.

26.Varela MJV, Coin-Carvalho JE, Carvalho LBC, Prado LBF, Prado GF. Restless Legs Syndrome in Brazilian patients: a qualitative analysis of psychosocial suffering and interdisciplinary attention. J Health Psychol 2013;18:1341-52. http://dx.doi.org/10.1177/1359105312439730

27.Hening WA, Allen RP, Washburn M, Lesage SR, Earley CJ. The four diagnostic criteria for Restless Legs Syndrome are unable to exclude confounding conditions (“mimics"). Sleep Med 2009;10:976-81. http://dx.doi. org/10.1016/j.sleep.2008.09.015

28. Foucault M. O Nascimento da Clínica. 6a. ed. Rio de Janeiro: Editora Forense Universitária, 2008, 252p.

29.Connor JR, Ponnuru P, Wang XS, Patton SM, Allen RP, Earley CJ. Profile of altered brain iron acquisition in restless legs syndrome. Brain 2011;134:95968. http://dx.doi.org/10.1093/brain/awr012

30.Chauí M. Merleau-Ponty: a obra fecunda. A filosofia como interrogação interminável. Cult-Revista Brasileira de Cultura, São Paulo: Ed. Bregantini, 2008, 168p. 